\title{
Orthodontic Appliances and Esthetics
}

\author{
Aakash Shah*, Purvesh Shah, Santosh Kumar Goje, Romil Shah, Bhumi Modi \\ Department of Orthodontics and Dentofacial Orthopedics, K.M. Shah Dental College and Hospital, \\ Vadodara, Gujarat, India
}

dai: https://doi.org/10.21467/ajgr.2.1.25-30

* Corresponding Author email: aakashshah108@gmail.com

\section{Article Histary}

Received: 19 March 2017

Revised: 8 April 2017

Accepted: 8 April 2017

Published: 10 April 2017

Student(s)

- Aakash Shah

Academic Year: 2016-17

Course Level: Master Degree

Course Name: Master of Dental Surgery (M.D.S.)

Course year: $3^{\text {rd }}$ year

Mentor(s)

- Purvesh Shah

- Santosh Kumar Goje

- Romil Shah

- Bhumi Modi

\begin{abstract}
Facial attractiveness plays a key role in orthodontic treatment. The esthetics of a patient may be hindered by wearing of orthodontic appliances. Recently, the orthodontic market has experienced phenomenal growth in the development and production of orthodontic appliances that are designed to appeal to the patient consumer. Traditionally, the options for bracket style or appliance design were considerably limited for both the patient and provider. However, a shifting paradigm toward dental esthetics, increased demand for orthodontic treatment, consumer driven desire of esthetic treatment alternatives, and a competitive orthodontic industry and profession have all contributed to the development and production of alternative orthodontic appliances and new bracket styles. Orthodontic patients and practitioners are now presented with a variety of treatment options previously unavailable. Just as each orthodontic appliance is unique in its esthetic qualities, each also has biomechanical benefits and potential limitations. For a practitioner providing bracket options for patients, selecting which bracket to offer becomes a function of both esthetics and functionality, the one will be esthetically acceptable to the patient and clinically efficient for the doctor. Though many studies have sought to compare and quantify the clinical efficiency of bracket systems, few studies have investigated the patient perception of appliance esthetics. This review discusses various aspects of orthodontic appliances relating to the esthetics of an individual.
\end{abstract}

Keywords: Facial esthetics, Orthodontics 


\section{Introduction}

Over the last decade, the prevalence of adults seeking orthodontic treatment has drastically increased. In the United States, it is estimated that approximately $30 \%$ of patients seen in orthodontic offices are 18 years or older [1]. In the United Kingdom, a survey of orthodontists revealed that public and private orthodontists start approximately 20 to 28 new adult patients each year [2]. According to the Wall Street Journal and the American Association of Orthodontists, approximately 1.2 million adults received orthodontic treatment in 2012; this was a 39\% increase from 1996 [3]. These increasing numbers of patients seeking orthodontic treatment raise questions about how orthodontic treatment might affect the lives of these patients. Though each patient has their own reason for starting treatment, most adults are self-motivated to begin treatment. Most commonly, patients present to the orthodontist with the desire to straighten their teeth and improve their smiles [4]. In 1998, Bergstrom et al. [5] surveyed over 200 adult patients to determine their perspectives of visible orthodontic appliances. Out of the total subjects surveyed, $67 \%$ of adults agreed that they will wear braces [5]. They stated that advances in ceramic brackets, clear aligners, as well as lingual appliances are demanded by adults who are self-conscious about wearing traditional appliances [3]. These new and esthetic appliances are acceptable to many adults, and patients are even willing to pay more for these alternative treatment modalities [6].

In addition to their esthetic concerns, many adult patients acknowledge other external factors like selfesteem and body image that prompt them to begin orthodontic treatment [4]. The WHO defines health as a "state of complete physical, mental, and social well-being" [7]. Several studies have demonstrated a correlation between dental malocclusions and a poor oral health quality of life [8,9]. Patients not only expect an improvement in their appearance with orthodontic treatment, but they anticipate an enhancement in confidence and self-esteem once they have completed the treatment [4]. There is some support for patients' positive expectations for treatment; Varela et al. [10] described an overall improvement of patient body image at just 6 months into orthodontic treatment and facial body image also improved after the conclusion of treatment [10]. Overall, patients demonstrate an improvement in self-esteem following treatment [4]. Thus, orthodontic therapy can enhance the patient's psychosocial, subjective sense of well-being [11].

There are various esthetic orthodontic appliances available for orthodontic treatment like ceramic brackets, lingual brackets, clear aligners, etc. to overcome the esthetic demands of adult patients. The ceramic brackets are esthetic brackets which are tooth colored. The lingual brackets are bonded on the lingual side of the teeth. They are not visible from the facial aspect. Therefore, the esthetics of an individual is not impaired. More recently, the thermoplastic clear aligners are used for relieving of mild to moderate crowding. They are colorless aligners, removable and user friendly. The patient has to wear a series of aligners for duration of about 18 months. Nowadays adults are more undergoing orthodontic treatment because of newer appliances and their concern for facial esthetics.

\section{Orthodontic Appliances and Esthetics}

In a classic 1972 article, Dion et al. [12] examined the theory that "What is beautiful is good." They demonstrated that attractive individuals are perceived as more socially desirable and professionally capable than less attractive individuals [12]. Attractive individuals are ascribed more social competence than unattractive individuals; other studies have demonstrated that this same trend is exhibited for ratings of effectiveness, adjustment, and intellectual competence [13]. While some researchers have questioned the generalizability of the Dion et al. study, overall, meta-analytic analyses demonstrate that individuals who are rated as being more attractive are evaluated more positively than unattractive individuals, and achieve improved life outcomes when compared to those rated as less attractive [14]. These findings generalize to the employment setting. In their meta-analysis, Hosoda et al. [14] assessed the effect of attractiveness on several job-related outcomes such as hiring, promotions, and performance evaluations. They concluded that the physical attractiveness of a person was consistently advantageous to that 
Shah et al., Adv.J. Grad. Res.; Vol. 2 Issue 1, pp: 25-30, July 2017

individual and there was a direct relationship between attractiveness and several of the career outcomes for both males and females. The advantage associated with attractiveness was conferred despite the amount of other job-relevant information presented to the reviewers such as performance reviews, interviews, etc. [14] Similarly, Jackson et al. [15] demonstrated an association between attractiveness and competence in the workplace and extended these findings to show that the attractiveness of individual had an even stronger effect on job outcomes if that individual's performance was low [15]. Agthe et al. [16] not only examined the influence of attractiveness on hiring decisions, but also evaluated the participants' preference for social interaction with individuals in the workplace of differing attractiveness. They found that participants preferred to interact with attractive individuals of the opposite sex, but these same tendencies did not exist for same sex interactions. Thus, the advantage conferred by attractiveness did not always apply when interacting with members of the same sex. Their findings indicated that the willingness of a participant to interact with the individual was associated with the decision to hire the individual, but attractiveness did not significantly influence the hiring decision [16].

Many studies have attempted to examine the relationship between dental appearance and social attractiveness ratings. For example, Newton et al. [17] examined the effects of apparent dental decay on the evaluation of a subject. Two hundred undergraduate students were given a photo of an adult male; half of the subjects received a photo stimulus with dental disease while the other half evaluated a photo that had no apparent disease. Overall, the individuals portrayed with a healthy, disease-free smile were judged to be more socially, intellectually, and psychologically competent than the individuals with visible dental disease [17]. Similarly, Beall et al. [18] altered a set of photographs to mimic the effects of restorative dentistry on an individual's dental appearance. Half of the photographs represented the subject's smile before cosmetic dental treatment; while the other half represented the smile after cosmetic dental treatment was completed. They found that the individuals pictured with altered smiles were regarded as more attractive, intelligent, and successful in their careers as compared to those with unaltered "before" smiles [18]. Thus, dental appearance can influence the psychosocial evaluation of an individual. Similar to the evaluation of dental health on attractiveness ratings, several studies have investigated the influence of a malocclusion on the assessment of an individual's attractiveness. Shaw et al. [19] modified the photos of 4 individuals, 2 attractive and 2 unattractive, to evaluate the differences in social attractiveness ratings with different conditions and positions of the incisors. They included photos with normal, crowded, protrusive, or missing incisors as well as the presence of a cleft lip. The photos of individuals with normal incisor relationships were rated significantly higher than those with malocclusions in perceived friendliness, social class, popularity, and intelligence. The females pictured were rated more harshly than their male counterparts. However, the overall facial attractiveness (attractive vs. unattractive) was a stronger predictor of perceived social attractiveness than dental appearance [19].

Adding to these findings was a study by Olsen et al. [20] who investigated the influence of several other types of malocclusion (deepbite, open bite, underbite, overjet, spacing and crowding) on the ratings of attractiveness, intelligence, and personality factors collectively in a sample of 889 photos of patients. They included photos that were manipulated to display excess overjet, negative overjet, a deep bite, an open bite, crowding, and spacing as well as photos with normal occlusion. The photos with a normal occlusion were rated as most attractive, intelligent, agreeable, and extraverted. The photos with negative overjet, representing a class III patient, were rated lowest in attractiveness, intelligence, and extroversion. Contrary to Shaw et al.'s study, the photographs of females were rated more positively than the males. Additionally, older, less educated subjects rated the photos more favorably than their younger, higher educated counterparts [20]. Taken together, these studies suggest that the presence of a dental malocclusion can influence how personal attributes are assigned. Pithon et al. [21] extended the past research on the influence of malocclusion to the workplace hiring practices for a commercial company. They compared the likeliness of being hired, intelligence, honesty, and efficiency at work for candidates with a malocclusion versus those with an ideal smile. Ten photos were manipulated to illustrate several different types of malocclusion; the same individual was also shown with an ideal occlusion. Adult 
subjects from a Human Resources company responsible for hiring applicants for jobs in sales were the raters. Ultimately, they found that the raters indicated that the individuals depicted in the photos with an esthetic smile were more likely to be hired than their counterparts with a malocclusion [21].

Facial features other than a malocclusion have also been shown to affect a rater's perception of a photograph of an individual. Madera et al. [22] examined the influence of a facial stigma, such as a scar or port wine stain, on the evaluation of an applicant in an interview. They used eye-tracking technology as well as subjective applicant ratings and recall from the interview to determine the implication of these stigmas on the reviewers. In keeping with earlier findings about malocclusions, they found that there was a significant effect of the stigma on the interviewer's visual attention to the applicant. When a stigma was present, the participants focused more of their attention on the area with the stigma. These facial characteristics were also found to potentially influence employment decisions; the participants who interviewed a facially stigmatized applicant rated the applicant lower and recalled less information about them after the interview [22]. In summary, an individual's facial features and perceived attractiveness which is hampered because of orthodontic appliances can influence several job-related outcomes. Several studies have examined the influence of fixed orthodontic appliances on the layperson's ratings of attractiveness. These studies have concluded that clear aligners and simulated lingual appliances are the most attractive treatment modality, followed by ceramic appliances and then metal appliances [6, 23]. Even older children tend to rate clear orthodontic appliances higher than younger children [24]. However, despite the increased ratings of attractiveness of ceramic brackets, attractiveness did vary with wire selection and tie variation [23]. Ceramic brackets with discolored ties were rated lower in overall acceptability when compared to other esthetic appliances [24].

In 2009, Berto et al. [25] examined the smile esthetics of several different versions of the same full-face photograph. Each photograph was manipulated to display a metal appliance, a clear appliance, rubber bands of varying colors, or missing maxillary premolars, simulating a common adult extraction pattern. Fifty orthodontists and fifty laypeople evaluated and rated the esthetics of the photos. The photos with visible extraction spaces had significantly lower attractiveness ratings, but the presence of a metal appliance did not affect the smile assessment. However, laypeople identified the esthetic brackets as less attractive than the metal appliance; this same bias did not exist within the orthodontist raters [25]. Jeremiah et al. [26] continued to investigate the influence of orthodontic appliance on the evaluation of a person's physical attractiveness, but they also assessed how the appliance would influence social attractiveness ratings. The investigators manipulated the photo of a young, female adult to simulate 5 scenarios: no appliance, fixed metal appliances, fixed ceramic appliances, fixed gold appliances, or clear aligners. They surveyed 125 adults; each subject rated one photo based on attractiveness, social competence, psychological adjustment, and intellectual ability. The authors found that the photos with no appliance or the clear aligner were rated as significantly more attractive than the other groups. Additionally, intellectual ability was rated higher for the photos with no appliance, the clear aligner, or the gold appliance. There were no differences in psychological adjustment or social competence ratings between groups [26].

Individuals with fixed orthodontic appliances also appear to judge their own attractiveness more harshly. Fonseca et al. [27] recruited 60 volunteers to evaluate themselves in a mirror with no appliance, a fixed metal appliance, and a fixed ceramic appliance. The subjects rated themselves most attractive with no appliance and least attractive with a metal appliance in place. The study continued with a peer evaluation of the photos under the same conditions; the photos were rated on beauty, intelligence, ridiculousness, extroversion, and success. They found that there were no significant differences in any rating between the photos with fixed appliance and those with no appliance. Interpersonal social and physical judgments were not influenced by the absence or presence of orthodontic appliances [27]. More recently the orthognathic surgery is performed along with lingual appliance to maintain the esthetics of an individual [28]. Nowadays vacuum-formed thermoplastic retainers (VFR) are used for the purpose of retention [29]. These are clear retainers and fulfill the esthetic demands of an individual. A CAD/CAM nickel-titanium 
Shah et al., Adv.J. Grad. Res.; Vol. 2 Issue 1, pp: 25-30, July 2017

lingual retainer named "memotain" is recently introduced in contrary to conventional fixed bonded lingual retainers [30]. Since the conventional bonded lingual retainer tends to break more, these newly invented "memotain" are successful in prevention of breakage. These retainers are lingually bonded in the patient so they are esthetically not visible.

\section{Conclusions}

As the number of adult orthodontic patients grows in the world, orthodontists must be able to address this population's complex treatment needs. Since the appearance of the selected orthodontic appliance is one of the patients' greatest concerns, clinicians must help the patient make an informed decision about the appliance they select. Patients will tend to judge themselves more critically than others will perceive them. However, the type of orthodontic appliance present can influence the appraisal of an individual's perceived intelligence. Gender biases may exist for different types of orthodontic appliances, both traditional appliances and newer esthetic appliances. Consequently, orthodontists must understand and explain the preconceptions associated with each type of appliance. Orthodontists must also educate their adult patients about social and psychological benefits of orthodontic treatment. The results of orthodontic treatment can improve esthetics, but also self-esteem, body image, and psychosocial aspects of the individual's life. The temporary appearance and use of any type of orthodontic appliance serves only as a necessary means to an end treatment goal.

\section{How to cite this article:}

Shah, A., Shah, P., Goje, S., Shah, R., \& Modi, B. (2017). Orthodontic Appliances and Esthetics. Advanced Journal of Graduate Research, 2(1), 25-30. doi: https://doi.org/10.21467/ajgr.2.1.25-30

\section{References}

[1] Proffit W, Fields H, Sarver D. Contemporary orthodontics. 5th ed. Canada: Elsevier; 2013, pg. 653.

[2] Cedro MK, Moles DR, Hodges SJ. Adult orthodontics--who's doing what? J Orthod. 2010;37(2):107-117.

[3] Reddy S. Why more adults are getting braces. Wall Street Journal. 2015. Available from: http://www.wsj.com/article email/whymore-adults-are-getting-braces-1444066342-1MyQjAxMTI1NzEyMTgxMjEwWj.

[4] Pabari S, Moles DR, Cunningham SJ. Assessment of motivation and psychological characteristics of adult orthodontic patients. Am J Orthod Dentofacial Orthop. 2011;140(6):e263-72.

[5] Bergstrom K, Halling A, Wilde B. Orthodontic care from the patients' perspective: Perceptions of 27-year-olds. Eur J Orthod. 1998;20(3):319-329.

[6] Rosvall MD, Fields HW, Ziuchkovski J, Rosenstiel SF, Johnston WM. Attractiveness, acceptability, and value of orthodontic appliances. American Journal of Orthodontics and Dentofacial Orthopedics. 2009;135(3):276.e1-276.e12.

[7] Constitution of WHO: principles. (n.d.). Retrieved April 06, 2017, from http://www.who.int/about/mission/en/

[8] Choi SH, Kim BI, Cha JY, Hwang CJ. Impact of malocclusion and common oral diseases on oral health-related quality of life in young adults. Am J Orthod Dentofacial Orthop. 2015;147(5):587-595.

[9] Hassan AH, Amin H. Association of orthodontic treatment needs and oral health related quality of life in young adults. Am J Orthod Dentofacial Orthop. 2010;137(1):42-47.

[10] Varela M, Garcia-Camba JE. Impact of orthodontics on the psychologic profile of adult patients: A prospective study. Am J Orthod Dentofacial Orthop. 1995;108(2):142-148.

[11] Gazit-Rappaport T, Haisraeli-Shalish M, Gazit E. Psychosocial reward of orthodontic treatment in adult patients. Eur J Orthod. 2010;32(4):441-446.

[12] Dion K, Berscheid E, Walster E. What is beautiful is good. J Pers Soc Psychol. 1972;24(3):285-290.

[13] Eagly AH, Ashmore RD, Makhijani MG, Longo LC. What is beautiful is good, but...: A meta-analytic review of research on the physical attractiveness stereotype. Psychol Bull. 1991;110(1):109-128.

[14] Hosoda M, Stone-Romero E, Coats G. The effects of physical attractiveness on job related outcomes: A meta-analysis of experimental studies. Person Psychol. 2003;56(2):431-462.

[15] Jackson LA, Hunter JE, Hodge CN. Physical attractiveness and intellectual competence: A meta-analytic review. Soc Psychol Q. 1995;58(2):108-122.

[16] Agthe M, Spörrle M, Frey D, Maner JK. Looking up versus looking down: Attractiveness based organizational biases are moderated by social comparison direction. J Appl Soc Psychol. 2014;44(1):40-45.

[17] Newton JT, Prabhu N, Robinson PG. The impact of dental appearance on the appraisal of personal characteristics. Int $J$ Prosthodont. 2003;16(4):429-434.

[18] Beall AE. Can a new smile make you look more intelligent and successful? Dent Clin North Am. 2007;51(2):289-97, vii.

[19] Shaw WC, Rees G, Dawe M, Charles CR. The influence of dentofacial appearance on the social attractiveness of young adults. Am J Orthod. 1985;87(1):21-26. 
Orthodontic Appliances and Esthetics

[20] Olsen JA, Inglehart MR. Malocclusions and perceptions of attractiveness, intelligence, and personality, and behavioral intentions. Am J Orthod Dentofacial Orthop. 2011;140(5):669-679.

[21] Pithon MM, Nascimento CC, Barbosa GC, Coqueiro Rda S. Do dental esthetics have any influence on finding a job? Am J Orthod Dentofacial Orthop. 2014;146(4):423-429.

[22] Madera JM, Hebl MR. Discrimination against facially stigmatized applicants in interviews: An eye-tracking and face-to-face investigation. J Appl Psychol. 2012;97(2):317-330.

[23] Ziuchkovski JP, Fields HW, Johnston WM, Lindsey DT. Assessment of perceived orthodontic appliance attractiveness. Am J Orthod Dentofacial Orthop. 2008;133(4 Suppl):S68-78.

[24] Walton DK, Fields HW, Johnston WM, Rosenstiel SF, Firestone AR, Christensen JC. Orthodontic appliance preferences of children and adolescents. American Journal of Orthodontics and Dentofacial Orthopedics. 2010;138(6):698.e1-698.e12.

[25] Berto PM, Lima CS, Lenza MA, Faber J. Esthetic effect of orthodontic appliances on a smiling face with and without a missing maxillary first premolar. Am J Orthod Dentofacial Orthop. 2009;135(4 Suppl):S55-60.

[26] Jeremiah HG, Bister D, Newton JT. Social perceptions of adults wearing orthodontic appliances: A cross-sectional study. Eur J Orthod. 2011;33(5):476-482.

[27] Fonseca LM, Araujo TM, Santos AR, Faber J. Impact of metal and ceramic fixed orthodontic appliances on judgments of beauty and other face-related attributes. Am J Orthod Dentofacial Orthop. 2014;145(2):203-206.

[28] Kyteas PG, McKenzie WS, Waite PD, Kau CH. Comprehensive treatment approach for condylar hyperplasia and mandibular crowding with custom lingual braces and 2-jaw surgery. Am J Orthod and Dentofacial Orthop. 2017;151(1):174-85.

[29] Kaklamanos EG, Kourakou M, Kloukos D, Doulis I, Kavvadia S. Performance of clear vacuum-formed thermoplastic retainers depending on retention protocol: a systematic review. Odontology. 2016 Jun:1-1.

[30] Kravitz ND, Grauer D, Schumacher P, Jo YM. Memotain: A CAD/CAM nickel-titanium lingual retainer. Am J Orthod and Dentofacial Orthop. 2017;151(4):812-5.

\section{Publish your research article in AIJR journals-}

$\checkmark$ Online Submission and Tracking

$\checkmark$ Peer Reviewed

$\checkmark$ Rapid decision

$\checkmark$ Immediate Publication after acceptance

$\checkmark$ Open Access (Articles freely available online)

$\checkmark$ Retain full copyright of your article.

Submit your article at journals.aijr.in 